\title{
A sensitivity study of the WRF model in wind simulation for an area of high wind energy
}

\author{
David Carvalho, Alfredo Rocha, Moncho Gómez-Gesteira, Carlos Santos
}

\begin{abstract}
The performance of the Weather Research and Forecast (WRF) model in wind simulation was evaluated under different numerical and physical options for an area of Portugal, located in complex terrain and characterized by its significant wind energy resource. The grid nudging and integration time of the simulations were the tested numerical options. Since the goal is to simulate the near-surface wind, the physical parameterization schemes regarding the boundary layer were the ones under evaluation. Also, the influences of the local terrain complexity and simulation domain resolution on the model results were also studied. Data from three wind measuring stations located within the chosen area were compared with the model results, in terms of Root Mean Square Error, Standard Deviation Error and Bias. Wind speed histograms, occurrences and energy wind roses were also used for model evaluation. Globally, the model accurately reproduced the local wind regime, despite a significant underestimation of the wind speed. The wind direction is reasonably simulated by the model especially in wind regimes where there is a clear dominant sector, but in the presence of low wind speeds the characterization of the wind direction (observed and simulated) is very subjective and led to higher deviations between simulations and observations. Within the tested options, results show that the use of grid nudging in simulations that should not exceed an integration time of 2 days is the best numerical configuration, and the parameterization set composed by the physical schemes MM5eYonsei UniversityeNoah are the most suitable for this site. Results were poorer in sites with higher terrain complexity, mainly due to limita-tions of the terrain data supplied to the model. The increase of the simulation domain resolution alone is not enough to significantly improve the model performance. Results suggest that error minimization in the wind simulation can be achieved by testing and choosing a suitable numerical and physical configuration for the region of interest together with the use of high resolution terrain data, if available.
\end{abstract}

\section{Keywords}

WRF model, Sensitivity analysis, Wind simulation, Boundary layer parameterizations, Terrain complexity, Wind energy

\section{Introduction}

The accurate simulation and prediction of the near-surface wind has been, in the recent past, a subject of the utmost importance and a target of intensive academic and ind ustrial research. The growing wind power industry and the increasing occurrence of extreme weather events are strongly supporting this interest in wind simulation, which is still a major challenge to atmospheric modellers involved in meteorological research and applications. Regional meteorological models are a very powerful and useful tool to study and simulate meteorological variables. These models have typically a broad range of configuration options available and this diversity presents its own problems, as identifying the best set of numerical, physical and computational options becomes highly complex due to high-dimensional, multi-modal and mostly nonlinear interactions that can occur (Nossent et al., 2011). Thus, one of the foremost challenges in establishing a model for use in a particular area is the determination of the most appropriate model configuration. Aside from the existence of a large array of available options, the best combination for one region is not necessarily applicable to another (Krieger et al., 2009). According to Hirabayashi et al. (2011), examining the sensitivity of a numerical model to changes in its configuration options constitutes an important evaluation exercise and this sensitivity analysis will allow, on the one hand, an improvement of the knowledge of how 
numerical simulation models work and, on the other hand, an identification of which model parameters need to be specified more accurately (Barnsley, 2007). Moreover, a sensitivity analysis can give to the modellers vital information about the use and influence of the several model parameters.

Atmospheric processes occur on various spatial and temporal scales ranging from $10^{-2} \mathrm{~m}$ to $10^{8} \mathrm{~m}$ and $10^{-1} \mathrm{~s}$ to $10^{8} \mathrm{~s}$ (Orlanski, 1975), and regional meteorological models are not designed to resolve these physical processes on all scales per construction. However, unresolved processes are considered in these models with the aid of physical parameterization schemes that apply several assumptions and approximations to simplify unresolved processes. These parameterizations typically include moist convection, atmospheric turbulence, radiative transfer, microphysics, soil and vegetation interaction. In the past few years a wide range of parameterization schemes have been implemented in climate models, which opens a broad range of choice in model configuration and provides an opportunity to identify deficiencies in these schemes by comparative evaluation.

The model chosen to conduct the simulations is WRF version 3.0.1 of the Advanced Research (ARW) solver, a widely used community mesoscale model developed by the National Centre for Atmospheric Research (NCAR). It represents the current state-ofthe-art in mesoscale model development, and was established as a successor to the long-standing Penn State/NCAR Fifth-Generation Mesoscale Model (MM5), sharing much of the same dynamics and model physics. A detailed description of this model can be found on Skamarock et al. (2008). This model offers multiple physics options that can be combined in different ways. The options typically range from simple and efficient to sophisticated and more computationally costly and from newly developed schemes to well tried schemes such as those in current operational models. WRF has a wide set of physical parameterizations available for microphysics, radiation (long wave and short wave), cumulus and related to the boundary layer: surface layer (SL), planetary boundary layer (PBL) and land surface model (LSM). Physical parameterization schemes interact non-linearly with each other and with the dynamical core of the model, and these complex relationships make the interpretation of model deficiencies very challenging. The fact that each of these schemes is based on many assumptions and these assumptions may fail, or give an inadequate response to certain synoptic forcing, limits their application and acts as a source of errors in the models (Awan et al., 2011).

Besides physical parameterization schemes and the unconfined empirical parameters within these schemes, there are other sources of errors in the numerical models. The dependence of numerical models on different numerical solvers, initial and boundary conditions, domain sizes and position, horizontal and vertical resolution, terrain and vegetation characteristics, along with nudging and assimilation techniques accounts for these errors in the results (Awan et al., 2011). Another important factor is the topography, which has a strong influence on the climate of a region. The substantial orographic features (w25 \% of earth's total dry land area) significantly influence the regional and global climate by changing the dynamics of the atmospheric circulation (Kapos et al., 2000), and interactions between the atmosphere and the land surface have considerable influences on weather and climate (Kumar et al., 2008). Within these terrain characteristics, the terrain complexity can play a major role in the surrounding atmospheric circulation. One of the parameters that strongly influence the terrain representation accuracy in the model is the resolution of the simulation domain.

As stated above, the interest in the wind simulation is nowadays a subject of not only meteorological relevance but also of increasingly interest to the wind power sector. Portugal is, currently, one of the world leading countries in installed wind generating power and still continues its growing, with one of the most ambitious goals in terms of wind power. In 2006, it was the second country in Europe with the highest wind power growth and in 2009 about $15 \%$ of its total energy consumption came from wind power, making Portugal the second country in the world in terms of wind power contribution to the total energy consumption. Over the recent past years, mesoscale simulations (this is, simulations at a regional scale in the order of hundreds to tens of $\mathrm{km}$ ) have found a number of applications in the wind energy field. These can be divided into three general groups: a) to determine the long-term local climatology in order to assess wind variability and the representativeness of local wind measurement campaigns; b) in short-term forecasting of wind farm production, combined with micro-scale models and/or statistical tools; and c) to obtain maps of average wind resource over large areas (province, state, country, continent) or virtual wind data series. The first type of application is becoming a common practice in most wind farm projects, in order to reduce uncertainty in annual energy production estimates. The second type, the use of mesoscale for forecasting, is a growing field, due to the increasing penetration of wind-generated electricity in many countries, and the subsequent need to forecast it for electrical grid balancing purposes and for promoters and clients to be able to operate in electricity markets. Finally, the third application is particularly useful for large scale energy or electrical grid planning and to help promoters differentiate between potential sites for wind farm installation, for greenfield or early-stage projects.

The use of mesoscale models for this kind of purposes has been, in the recent past, a subject of intensive research. Studies like Byrkjedal and Berge (2008), Chagas et al (2009) and Soares et al. (2010) backup the interest of the use of meteorological models, and specifically the WRF model, in the wind simulation for wind energy purposes. These considerations show the importance of the wind power industry in Portugal, being also noticeable the lack of published literature that focuses on a detailed testing and analysis of these models performance on the wind simulation in Portugal, especially within a wind power context.

The traditional meteorological studies regarding wind simulation typically focus on the $10 \mathrm{~m}$ above ground level (a.g.l.) wind and on spatial areas that present extreme or unusual meteorological features, while studies about wind energy assessment are more focused in higher wind heights (typically between 40 and $100 \mathrm{~m}$ a.g.l.) and in specific areas that are characterized by higher mean wind speeds, normally placed in mountainous zones. These areas are typically characterized by significant terrain complexity. The choice to simulate the near-surface wind in one area with typical features for wind energy exploration will allow the assessment of the WRF model performance at an area and wind heights that are normally out of the scope of the traditional meteorological studies, but that can become highly attractive for wind power agents.

Following the above mentioned considerations, it is the aim of this work to test the WRF model options concerning numerical and physical aspects, together with the influence of the domain resolution and terrain complexity on the model performance in the wind simulation at $60 \mathrm{~m}$ a.g.l., applied in an area of Portugal with typical features for wind power exploration.

\section{Methodology \\ 21. Initial and boundary conditions}

The initial and boundary conditions supplied to the model were driven by the National Centres for Environmental Prediction (NCEP) Final Operational Globa Analysis, with $1^{\circ}$ of spatial resolution (both in latitude and longitude) and $6 \mathrm{~h}$ of temporal sampling. The data sets of static fields (topography, land use, land-water 
masks, land use/land cover classification, albedo) were obtained and interpolated from the NCAR database, with a resolution of $30^{00}$ for all simulation domains.

Time-varying SSTs were also supplied to the model, being obtained from the real-time, global, sea surface temperature analyses database from NCEP. These daily SST analyses have a spatial resolution of $0.5^{\circ}$ (both in latitude and longitude).

\section{Simulation domains}

The simulation domains are shown in Fig. 1. The WRF model is built over a parent domain (D1) with $90 \mathrm{~km}$ of spatial resolution, covering all of the Iberian Peninsula and a portion of the North-Western Atlantic Ocean. The first nested domain (D2), with a spatial resolution of $18 \mathrm{~km}$, comprises the Northern and Central part of the Portuguese territory. The innermost domain (D3) has a spatial resolution of $3.6 \mathrm{~km}$ and it is focused on the chosen area to simulate, located in central Portugal. The vertical structure of the model contains 27 layers.

All domains are centred in a point with coordinates: Latitude $1 / 4-08^{\circ} 32^{0} 39^{\infty}$; Longitude $1 / 439^{\circ} 55^{0} 28^{00}$ and they interact with each other through a two-way nesting strategy. All the tests performed in this work consider as simulation domain the domain D3, except the test related to the effect of the increase of the simulation domain resolution. For this test, a new simulation was performed for 4 nested domains with 50 vertical levels, where the innermost one (D4) has a spatial resolution of $1.2 \mathrm{~km}$.

\section{Chosen area and wind measuring station}

Following the objectives mentioned in Section 1, an area located on the central Portuguese territory well known by its wind resource, where several wind farms are currently in operation, was chosen to perform the tests with the WRF model. This choice was based on the local terrain characteristics (typical features for wind energy exploration, characterized by its high terrain complexity and topography) and also on the measured wind data available in this area, at a typical wind height considered in the wind power studies (60 m a.g.l.), consequence of several wind measurement campaigns conducted by wind power investors.

Data from three wind measuring stations were used in this work to evaluate the model simulations. These wind measuring stations collect data of the wind speed and direction at $60 \mathrm{~m}$ a.g.l., with a sampling time resolution of $10 \mathrm{~min}$. The months of January and June of the year 2008 were used for the model validation. The choice of these months is related with data availability and also with the purpose to study the performance of the model physical options in a winter and a summer month. In all the performed simulations, wind speed and direction time series for the height of $60 \mathrm{~m}$ a.g.l. and with $10 \mathrm{~min}$ of temporal sampling were recorded to allow a direct comparison with the available observational data. The simulated time series for the points were obtained through interpolation using the nearest grid points.

The stations are designated as stations WS1, WS2 and WS3 and they are located within the chosen area of simulation, inside domain D3. However, the stations and the respective data belong to private companies and their exact locations cannot be disclosed due to data usage restrictions. Nevertheless, it is possible to show in Fig. 2 their relative positions (stations WS2 and WS3 are located at approximately $14 \mathrm{~km}$ southeast of WS1) and also the local altimetry, showing that the wind measuring stations are placed in mountain areas, with a complex surrounding topography. All the tests performed in this work use the data belonging to station WS1 for evaluation purposes, and in Sections 2.4.3 and 3.3 data from stations WS2 and WS3 were also used for model evaluation.

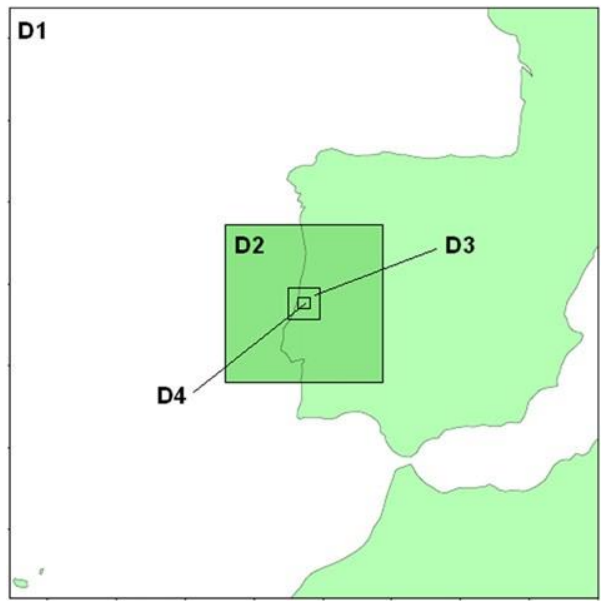

Fig. 1. Simulation domains.

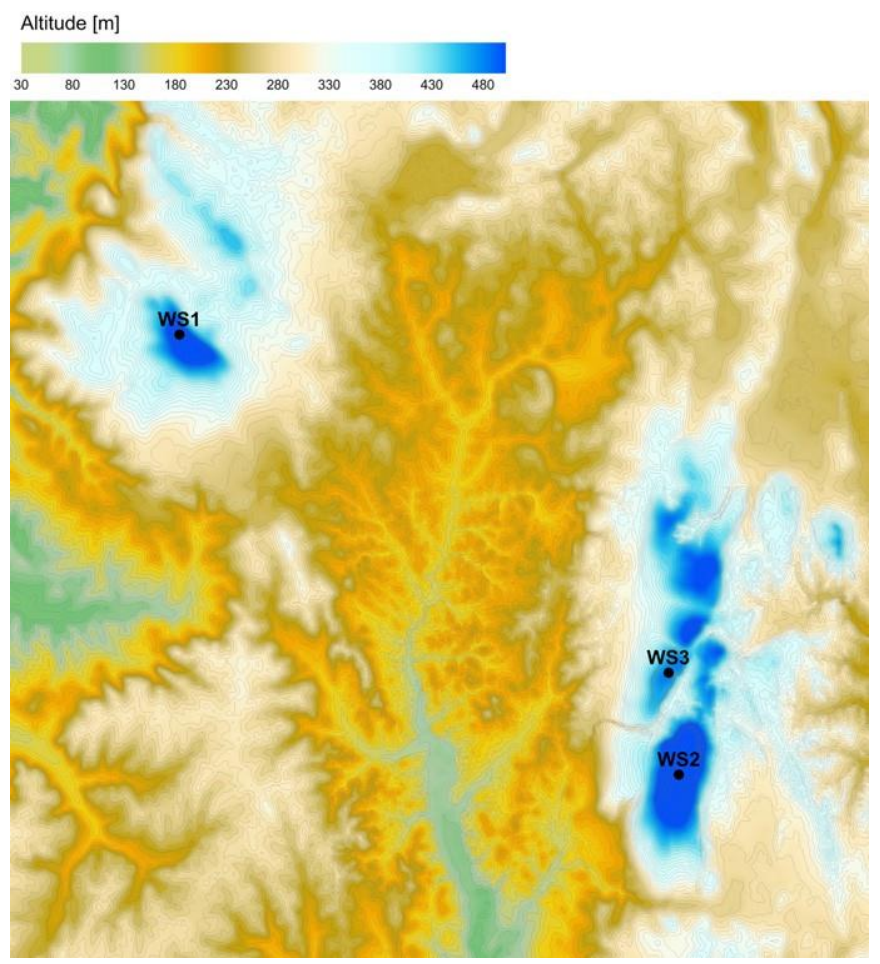

Fig. 2. Wind measuring stations.

\section{Design of the simulations}

The sensitivity tests performed in this work are divided into different categories: numerical options; physical options; influence of the terrain complexity and finally the influence of the simulation domain resolution. Series of month-long simulations with the WRF model were conducted and compared to measured wind data to attempt to identify the best performing options for this region. In order to extract the simulated wind time series at the points that coincide with the locations of the meteorological stations, horizontal and vertical interpolation was performed using the closest simulation grid points. The horizontal interpolation is made one time (as the WRF horizontal grid is constant in time) and the vertical interpolation is made for every model output timestamp, since the heights of the model vertical levels vary in time.

The methodologies followed to perform these tests are described in the next sub-sections.

\subsubsection{Numerical options}

It is known that numerical weather prediction models have a tendency to diverge in their simulations after some integration time, typically 2 or 3 days. Moreover, in a relatively long simulation the model tends to accumulate truncation errors. When the objective is to simulate longer periods of time, it may be preferable to perform segmented simulations (several independent shorter simulations) that, together, complete the desired period of simulation. For that, several " 2 -day restarted" simulations were performed that, in together, complete the desired period of simulation. Each " 2 -day re-started" run has 2 days and $12 \mathrm{~h}$ of integration time, being that the first $12 \mathrm{~h}$ of integration were considered as spin-up period of the model and disregarded. In this test, fifteen "2-day re-started" simulations were performed to complete one month-long simulation.

Another option offered in the WRF model, related to the possible divergence of the model due to long simulations periods, is to use nudging techniques on the simulations. Nudging, also known as Newtonian relaxation, is an option of WRF in its four-dimensional data assimilation (FDDA) system, which consists in methods of keeping simulations close to analyses and/or observations over the integration period. When this option is selected, results from the model equations or model state, are relaxed towards the observed values, or observed state. The observed state may be represented by gridded analyses, which are interpolated to the model's current time step (Stauffer and Seaman, 1990). There are two types of FDDA that can be used separately or in combination. Grid (or analysis) nudging consists in a specifically three-dimensional analysis nudging whereby the atmospheric model is nudged towards time and space interpolated analyses using a point by point relaxation term, simply forcing the model simulation towards a series of analyses grid-point by grid-point. Observational (or station nudging) locally forces the simulation towards observational data. These methods provide a four-dimensional 
Table 1

Numerical configurations.

\begin{tabular}{llll}
\hline Numerical options & A.1 & A.2 & A.3 \\
\hline Continuous & Yes & Yes & No \\
2-Day restarted & No & No & Yes \\
Grid nudging & No & Yes & Yes \\
\hline
\end{tabular}

analysis that is somewhat balanced dynamically, and in terms of continuity, while allowing for complex local topographical or convective variations. More details about these techniques can be found on Skamarock et al. (2008) and Stauffer et al. (1991). The option to use grid nudging will be tested here, but the option to use observational nudging, although very interesting, is outside of the scope of this work.

The possibility of model divergence, together with the error accumulation due to truncation issues, during its integration time is studied in this section, testing the use of segmented simulations and grid nudging in the wind simulation. These options are designated from now on as numerical options. It is important to mention that this work performs simulations of the wind, and not forecasts. Therefore, the model has available boundary conditions for the entire simulation period and it is not expected that the simulations will diverge during the integration time. Nevertheless, it is interesting to study the influence of these numerical options in the final results.

In order to test the above mentioned two numerical options, three different simulations are performed, here designated as simulations A.1, A.2 and A.3. These simulations will be compared with the observations taken from the meteorological station WS1, being that both simulations and observed data refer to the month of January 2008 and to the height of $60 \mathrm{~m}$ a.g.l. To better visualize the differences between the simulations, Table 1 describes the numerical configuration of each simulation.

The KaineFritsch scheme (Kain and Fritsch, 1990, 1993) is used by the model to parameterize cumulus physics. It is applied only on the larger domains (D1 and D2), as vertical fluxes due to updrafts and downdrafts and compensating motion outside the clouds can be resolved explicitly at grid sizes of approximately $5 \mathrm{e} 10 \mathrm{~km}$ (Skamarock et al., 2008). The remaining physical options are used in the three simulation domains. In all these simulations, the physical options are the same and are described in Table 2

\subsubsection{Physical options}

In this section, it is intended to test the physical options (parameterizations) of the WRF model. Since this work is centred in the near-surface wind simulation, the physical options related to the boundary layer processes parameterizations (SL, PBL and LSM) are the ones that will have a larger influence on an accurate near-surface wind simulation. Although more physical options are available in the model (for cumulus, radiation, microphysics, etc.), it is not feasible or necessary to include all the model configuration options in the sensitivity analysis to obtain an efficient model configuration optimization (Nossent et al., 2011).

Regional models require SL, PBL and LSM parameterizations to represent the transfer of heat, moisture and momentum between the surface and atmosphere (Gilliam and Pleim, 2010). The PBL scheme implemented in a model plays a decisive role on the accuracy of forecasted state and flow within the PBL because the wind varies according to the stability and baroclinic instability of the PBL. Furthermore, thermal stability (influences the vertical exchange of momentum), height of PBL (impact on the wind shear) and entrainment of the free atmospheric air into the PBL (determines the momentum, heat, and moisture exchanges at the top of the PBL (Arya, 1988)) strongly influence the wind distribution in the PBL.

Considerable progress has been made during the last decades with the aim either to develop new or to improve existing PBL schemes (Mellor and Yamada, 1974; Blackadar, 1979; Zhang and Anthes, 1982; Janjic, 1994; Hong and Pan, 1996; Shafran et al., 2000, Gilliam and Pleim, 2010). SL is the lowest part of the atmosphere, typically about a tenth of the height of the PBL where surface fluxes of scalars

Table 2

Physical options (parameterizations) used in simulations A.1, A.2, and A.3.

\begin{tabular}{ll} 
Physical options (parameterizations) & \\
\hline SL & MM5 \\
PBL & Yonsei University \\
LSM & Noah \\
Long-wave radiation & Rapid Radiative Transfer Model \\
Short-wave radiation & Dudhia \\
Cumulus & KaineFritsch \\
Microphysics & WRF Single-Moment 6-class \\
\hline
\end{tabular}

Table 3

Available schemes for each parameterization.

\begin{tabular}{ll}
\hline Parameterization & Available schemes \\
\hline SL & MM5, ETA, PleimeXiu \\
PBL & Yonsei University, MelloreYamadaeJanjic, ACM2, RUC \\
LSM & Noah, RUC, 5-layer, PleimeXiu \\
\hline
\end{tabular}

and momentum, nearly constant with height in this layer, dominate dynamics and physics. Vertical profiles of scalars and wind are determined by the MonineObukhov similarity theory. LSM schemes combine atmospheric information from the SL scheme with land surface properties (dependent on land uses) to evaluate the vertical transport done in the PBL schemes, which has a direct influence on the estimation of the PBL height (Han et al., 2008).

There are several alternative schemes available for each parameterization related to the boundary layer (Skamarock et al. (2008)). SL, PBL and LSM parameterizations are treated separately by the WRF model, however, they strongly interact between themselves. Due to this dynamic interaction, the choice of one scheme will determinate the choice of the remaining ones. Following the guidelines in Skamarock et al. (2008), the SL MM5 scheme has to be used together with the PBL Yonsei University scheme (YSU), the SL ETA scheme has to be used together with the PBL Mellore YamadaeJanjic scheme (MYJ) and the SL PleimeXiu (PX) scheme has to be used with the PBL Asymmetric Convective Model (ACM2) scheme. In addition, the SL PX and PBL ACM2 schemes have to be used together with the LSM PX scheme. Table 3 presents the available schemes for each PBL related parameterization.

In published literature, one can find an extensive list of different parameterization schemes depicting the same physical process, and several studies were conducted aiming to investigate the model performance on the simulation of meteorological variables under different physical parameterization schemes (Awan et al., 2011; Chigullapalli and Mölders, 2008; Gallus and Bresch, 2006; Gilliam and Pleim, 2010; Gilliam et al., 2007; Hutchinson et al., 2005; Jankov et al., 2005, 2007; Krieger et al., 2009). Challa et al. (2009) performed a simulation study of mesoscale coastal circulations in Mississippi Gulf coast with the WRF model, concluding that the YSU scheme shows improvement over MYJ scheme in the simulation of internal boundary layer characteristics and the overall performance of predicted mean variables. Challa et al. (2007), in its sensitivity experiments with WRF-CMAQ for air quality, showed that surface wind speed and wind direction are better simulated by the YSU PBL and Noah LSM, and also that YSU PBL along with Noah LSM give realistic meteorological predictions in the lower atmospheric region. Also winds, temperature and mixing height near the coast are better simulated with the above combination. For the Iberian Peninsula, that includes Portugal and Spain a detailed sensitivity analysis to WRF model was performed by Borge et al. (2008), testing 23 alternative model configurations, including PBL schemes, microphysics, LSM, radiation schemes, sea surface temperature (SST) and nudging techniques. They concluded that the YSU PBL option representation of the turbulent transport in the boundary layer improves the performance of other schemes, proving the importance of sensitivity studies to obtain a "best case" model configuration. For the Portuguese territory, Ferreira et al. (2008) performed a sensitivity study of the WRF surface wind, temperature and water vapour mixing ratio simulations, using different physical schemes. They concluded that the variation of the SL and PBL schemes have a significant influence on the wind prediction (especially for cold seasons) and also that the SLePBL parameterization set MM5eYSU is the one that presents better results in the wind simulation. As stated in Shin and Hong (2011), one of the major ingredients of the YSU algorithm is the explicit treatment of entrainment processes at the top of the PBL and at the inversion layer an asymptotic entrainment flux term proportional to the surface flux is included (see Noh et al., 2003 for more details).

Following the above mentioned guidelines for the choice of the parameterization schemes, three simulations were performed (B.1, B.2 and B.3) that use different schemes for the SL, PBL and LSM parameterizations. The remaining physical options regarding radiation, cumulus and microphysics are the same for the three simula tions. The physical configuration of each simulation is described in Table 4. It should

Table 4

Physical configuration of the simulations.

\begin{tabular}{llll}
\hline Parameterization & B.1 & B.2 & B.3 \\
\hline SL & MM5 & ETA & PX \\
PBL & YSU & MYJ & ACM2 \\
LSM & Noah & PX \\
Long-wave radiation & Rapid Radiative Transfer Model & \\
Short-wave radiation & Dudhia & \\
Cumulus & KaineFritsch & \\
Microphysics & WRF Single-Moment 6-class & \\
\hline
\end{tabular}



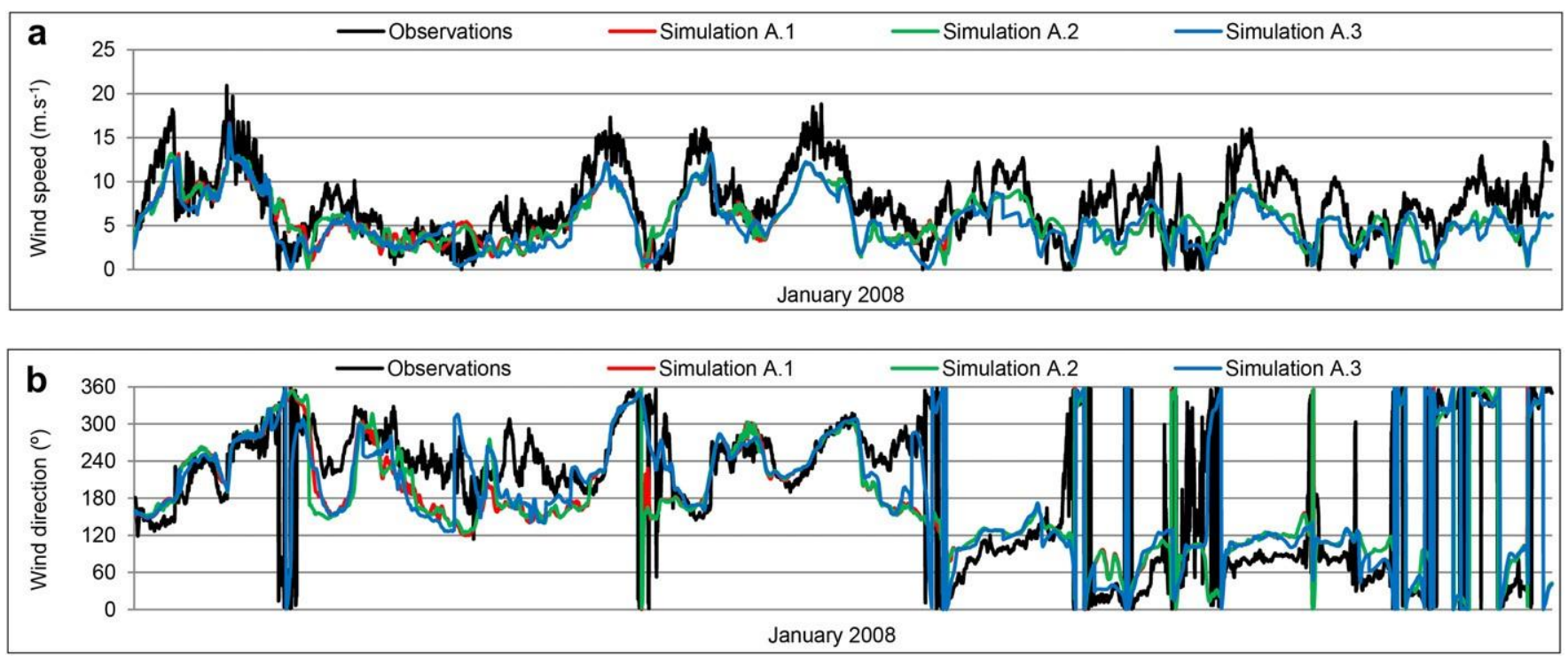

Fig. 3. Wind speed (a) and direction (b) time series e January 2008.

be noted that simulation B.1 consists in simulation A.3. Its terminology was changed to clearly separate the aspects under evaluation in each section.

In the same way as described in the previous section, the physical options are applied in the three simulation domains except the one regarding cumulus, which is not used in the innermost domain. As stated above, this parameterization is applied only on the larger domains (D1 and D2), as vertical fluxes due to updrafts and downdrafts and compensating motion outside the clouds can be resolved explicitly at grid sizes of approximately $5 \mathrm{e} 10 \mathrm{~km}$ (Skamarock et al, 2008). In order to test the parameterizations performance in a winter and a summer month, the three simulations were performed for the months of January and June, and compared to observational data obtained from WS1 in these two months.

2.4.3. Terrain complexity

It is widely accepted that one of the main limitations of regional meteorological models is their weak representation of the real terrain (topography, roughness, etc.), due to poor resolution/quality of the terrain data supplied to the model and/or insufficient resolution of the simulation domain. This means that the model considers the terrain much smoother than it is in reality: the mountains are represented with lower elevation and, oppositely, the valleys are considered with higher elevation, making the topography much smoother than it is in reality. This difference between real and model represented terrain will be higher the more complex is the real terrain. Consequently, the model should have a better performance in terrains that are less complex in reality, because its representation in the simulation domain is closer to the real terrain characteristics. As stated by Wakes et al. (2010) the use of simplified geometry in the topography description is not enough for accurate simulation purposes, since it is the topography that has a significant impact on the wind flows.

In order to evaluate the influence of the terrain complexity in the quality of the model performance, and using the simulation performed for the point B.1, two new locations were considered: simulation point C.2 is located in smoother terrain and coincides with the location of wind measuring station WS3; and the simulation point C. 1 is situated in a location with a higher terrain complexity and coincides with the location of wind measuring station WS2. Simulation point B.1 is compared, as until now, with the observations collected in wind measuring station WS1 and this point has an intermediate terrain complexity when compared to C.1 and C.2 simulation points. The simulation period is, again, January 2008.
2.4.4. Simulation domain resolution

In this section, it is intended to test if an increase of the simulation domain resolution can improve the terrain representation in the model and, thus, the model results. For this, a new simulation domain was built, described and represented in Section 2.3 and Fig. 1. The new simulation that considers this higher resolution domain, designated as D.1 (do not mistake with the label of domain 1, which is D1 and not D.1), has the same numerical and physical configuration of simulation B.1, as well as the simulation period e January 2008.

While the refined horizontal resolution aims to better represent the terrain in the model (from 3.6 to $1.2 \mathrm{~km}$ ), the increased vertical resolution (with additional 23 vertical layers) offers an enhanced resolution of the lower atmosphere especially focused on the boundary layer.

\section{Validation of the model}

A numerical weather prediction (NWP) model can be validated according to different methodologies that, all together, complement themselves (Pielke, 2002). In the present case, the goal is to validate the model using meteorological observations that represent the real state of the variables to simulate. To evaluate the model performance, three statistical parameters will be used:

The Root Mean Squared Error (RMSE),

$$
\text { RMSE - }\left[\frac{1}{N} \sum_{i=1}^{N}\left(\Theta_{i}\right)^{2}\right]^{t}
$$

where

$\theta_{i}^{i}-\theta_{i}^{x}-\theta_{i}^{\alpha i}$

represents the deviation between one individual value of the wind speed simulation and the observed wind speed in the same place and time instant and $N$ is the total number of pairs of values simulation-observation.

For the wind direction, which is a circular variable and not a linear one, Q' takes a different expression due to the fact that the absolute deviation of the wind direction cannot exceed $180^{\circ}$ in modulus. Following Ferreira et al. (2008), for this case Q' is given by

$$
\theta_{i}-\theta_{i}^{x}-\theta_{i}^{x d}\left[1-360 / \mid \theta_{i}^{x}-\theta_{i}^{a b}\left[\text {, if }\left|\theta_{i}^{x}-\theta_{i}^{p b}\right|>180^{\circ}\right.\right.
$$

Table 5

\begin{tabular}{|c|c|c|c|c|c|c|}
\hline \multirow[t]{2}{*}{ Numerical options } & \multicolumn{2}{|l|}{ RMSE } & \multicolumn{2}{|l|}{ Bias } & \multicolumn{2}{|l|}{ STDE } \\
\hline & Speed $\left(\mathrm{m} \mathrm{s}^{-1}\right)$ & Direction $\left(^{\circ}\right)$ & Speed $\left(\mathrm{m} \mathrm{s}^{-1}\right)$ & Direction $\left(^{\circ}\right)$ & Speed $\left(\mathrm{m} \mathrm{s}^{-1}\right)$ & Direction $\left(^{\circ}\right)$ \\
\hline Simulation A.1 & 3.11 & 56.02 & -1.69 & -3.09 & 2.61 & 55.93 \\
\hline Simulation A.2 & 3.09 & 57.37 & -1.68 & -2.78 & 2.59 & 57.30 \\
\hline Simulation A.3 & 3.16 & 47.07 & -2.18 & -3.85 & 2.29 & 46.91 \\
\hline
\end{tabular}

Wind speed and direction statistical evaluation parameters e January 2008 

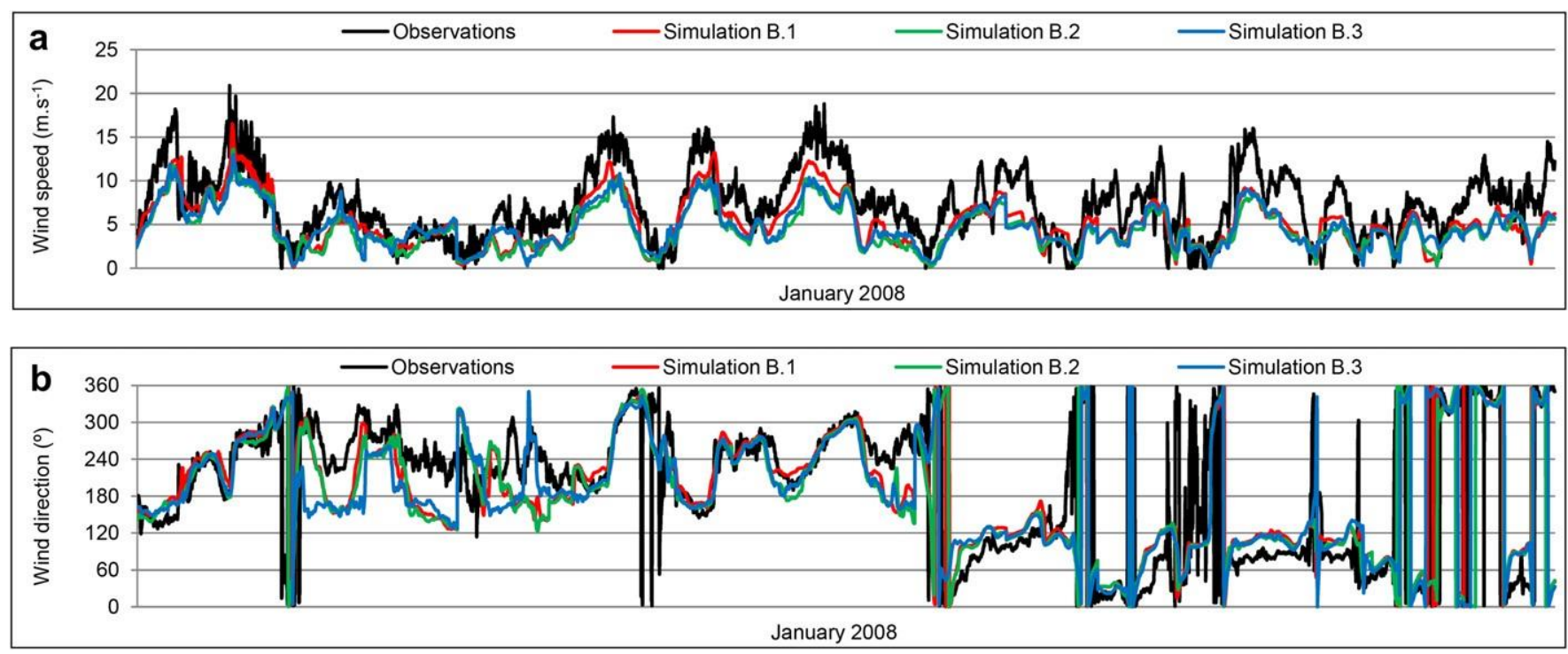

Fig. 4. Wind speed (a) and direction (b) time series e January 2008.

It is also defined that, for Northern Hemisphere, a positive Q' represents a clockwise deviation and a negative $Q^{\prime}$ an anti-clockwise deviation. The Bias,

$$
\text { nias }-\frac{1}{N} \sum_{i=1}^{N} \theta_{i}^{\prime}
$$

allows the evaluation of the data tendency. If it is positive the simulated values tend to be an overestimation of the real values, if it is negative the simulated values tend to be an underestimation of the real ones. For the wind direction, a positive/negative Bias means a clockwise/anti-clockwise deviation.

The Standard Deviation Error (STDE),

$$
\text { STDE }-\left[\frac{1}{N} \sum_{i=1}^{N}\left(\theta_{i}-\frac{1}{N} \sum_{i=1}^{N} \theta_{l}\right)^{2}\right]^{t}-\left[(\text { RMSE })^{2}-(\text { Bias })^{2}\right]^{+}
$$

\section{is very useful to evaluate the dispersion of the error.}

Priority will be given to the values of STDE, and this assumption comes from the fact that, even if a simulation has a high RMSE or Bias, if the STDE is low it means that the error is somewhat constant and can be seen as a kind of offset and the simulation physics is correct. If a simulation has a high STDE, the error is random and the simulation has low physical meaning, even if it has a relatively low RMSE or Bias.

\section{Results and discussion}

\subsection{Numerical options}

The possibility to use the grid nudging together with segmented simulations was evaluated in this section. The wind speed and direction time series of the three simulations described in Section 2.4.1, together with the observed data for the month of January 2008, are depicted in Fig. 3 and the respective statistical evaluation parameters are presented in Table 5 .

According to Fig. 3, it is noticeable that the model is able to accurately reproduce the local wind regime, both in terms of speed and direction. There is an underestimation of the wind speed in all simulations, and also deviations in the wind direction. There is a tendency for this deviation to be anti-clockwise (negative Q') if the observed wind direction is between 200 and $340^{\circ}$ and clockwise (positive Q') to the remaining wind directions. The statistical evaluation parameters presented in Table 5 show that simulation A.3 is the one that presents better overall results, since it has lower STDE despite the fact of the higher RMSE and Bias in the wind speed.

Considering the above mentioned results, the use of the grid nudging option together with 2 -day restarted simulations is,
among the options here tested, the best numerical configuration for

the model. The simulations performed from now on will have this numerical configuration.

\subsection{Physical options}

After the determination of the best numerical configuration of the model, the next step is to determine which set of physical options (parameterizations) offers the best results, for a winter and a summer month. The results for the month of January 2008 are presented in Fig. 4 and Table 6.

For this case, simulation B.1 seems to be the closest to the observations, both in terms of wind speed and wind direction. Again, in all simulations there is an underestimation of the wind speed together with a deviation in the wind direction, anticlockwise if the observed wind direction is between 200 and $340^{\circ}$ and clockwise to the remaining wind directions. The statistical evaluation parameters presented in Table 6 confirm that the simulation B.1 is the one with better results, due to the lower RMSE, Bias and STDE values in wind speed and direction.

For the month of June 2008, the results are presented in Fig. 5 and Table 7 .

Table 6

\begin{tabular}{|c|c|c|c|c|c|c|}
\hline \multirow[t]{2}{*}{ Physical options } & \multicolumn{2}{|l|}{ RMSE } & \multicolumn{2}{|l|}{ Bias } & \multicolumn{2}{|l|}{ STDE } \\
\hline & Speed $\left(\mathrm{m} \mathrm{s}^{-1}\right)$ & Direction $\left(^{\circ}\right)$ & Speed $\left(\mathrm{m} \mathrm{s}^{-1}\right)$ & Direction $\left(^{\circ}\right)$ & Speed $\left(\mathrm{m} \mathrm{s}^{-1}\right)$ & Direction $\left(^{\circ}\right)$ \\
\hline Simulation B.1 & 3.16 & 47.07 & -2.18 & -3.85 & 2.29 & 46.91 \\
\hline Simulation B.2 & 3.73 & 48.53 & -2.84 & -8.12 & 2.42 & 47.85 \\
\hline Simulation B.3 & 3.50 & 51.98 & -2.57 & -9.74 & 2.38 & 51.06 \\
\hline
\end{tabular}

Wind speed and direction statistical evaluation parameters e January 2008 

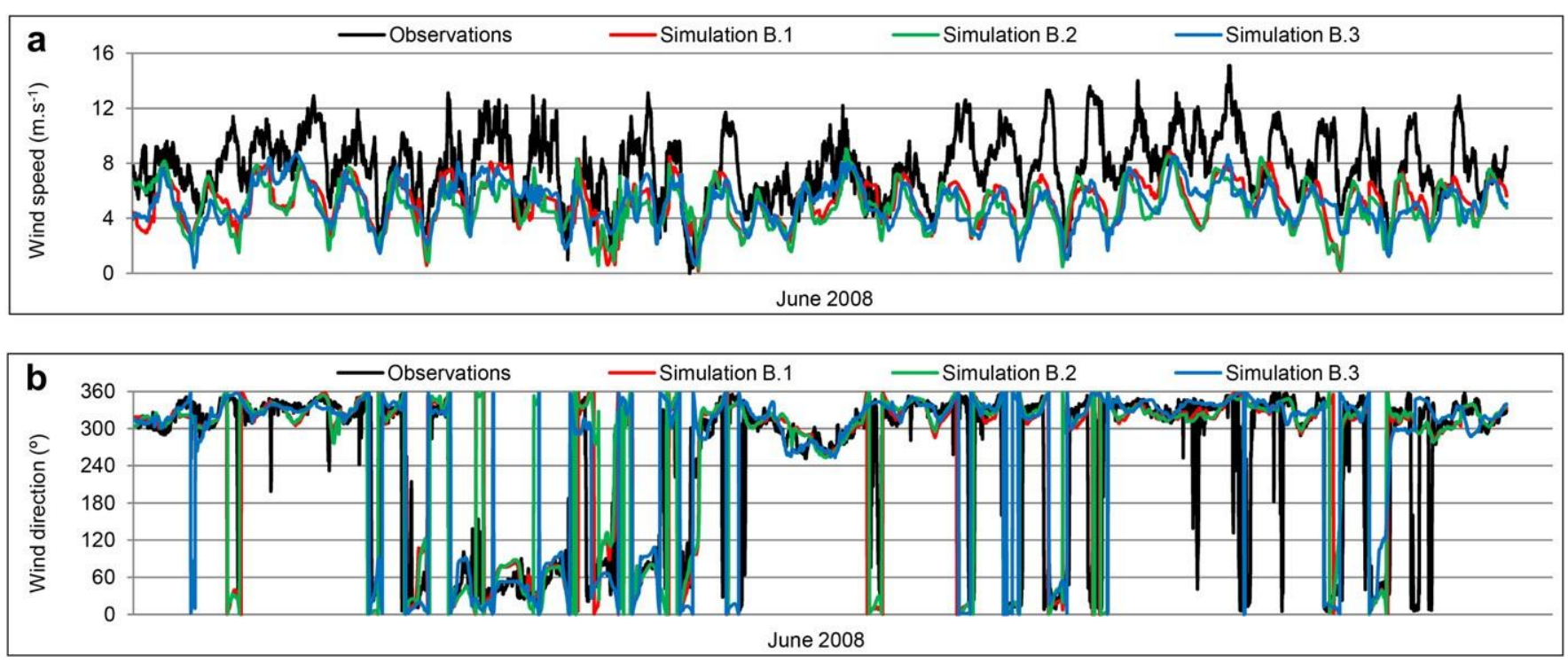

Fig. 5. Wind speed (a) and direction (b) time series e June 2008.

The model behaviour appears to be somewhat worse in the simulation of the wind speed in June, since the speed underestimation seems to be more evident in all simulations. The opposite is seen for the wind direction simulations, which are closer to the observed values, with lower deviations when compared to the January simulations. Simulation B.3 is the one that presents better results, due to the lower STDE for the wind speed and wind direction.

Considering these results, the first fact that becomes clear is that the model is somewhat sensitive to whether it is simulating warm or cold periods. Globally, the parameterization set MM5e YSUeNoah is the one with best global results, since it has the best accuracy in January and also presented good results in the simulation of June, with statistical parameters close to the ones obtained with the set PXeACM2ePX.

As expected according to the referred literature in Section 2.4.2, the SL and PBL schemes set YSUeMM5 are the ones that typically present better results. However, the better performance of the parameterization set composed by PXeACM2ePX in the wind simulation for June was expected. It is referred in Gilliam and Pleim (2010) that these physics schemes are particularly recommended to simulate warm season meteorology, since PX SL and PBL schemes together with the ACM2 LSM have a better behaviour in simulating warm seasons, because in cold seasons these schemes have a tendency to consider an excessive cloud coverage at the top of the PBL, which has a significant impact in the maximum daily temperature in some areas. It can be noted that the MYJ parameterization set is the one with poorer results for both months. As stated by Pagowski (2004), this scheme fails to sufficiently transfer heat between the surface and the atmosphere, since the temperature difference between the atmosphere and the surface is several times larger than the corresponding value prescribed by the similarity. In this scheme, the gradient between the atmosphere and the surface is too steep compared to the similarity, and above the SL, the heat flux is insufficient for this scheme. The MYJ scheme is clearly the most decoupled from the surface in terms of heat transfer, since temperature gradient between the surface and the atmosphere is too steep compared to the similarity.

Another visible aspect when comparing the results for January and June is the presence of a diurnal frequency signal in the wind speed time series. This kind of wind speed oscillations, which are a reflex of the higher influence of the boundary layer processes in the local circulation regimes, can be due to terrain-induced thermal circulations that are generally observed in mountain areas, especially in warm seasons. During daytime, the air adjacent to the slope is warmer than the free air at the same elevation, resulting in a horizontal temperature gradient that induces a thermal circulation along the slope that generates anabatic upslope winds. The opposite conditions prevail during night time, producing katabatic flows (Papanastasiou et al., 2010).

In order to obtain a better quantitative and qualitative perspective of the model performance for these two months, a more detailed analysis was performed throughout the visualization of occurrences and energy wind roses, together with wind speed histograms for the optimal simulations (B.1 for January, and B.3 for June). The energy wind rose arises as a consequence of the wind speed combined with the wind direction, since the amount of energy contained in the wind flow is a product of the wind speed and its sectorwise distribution depends of the wind direction distribution. It is especially meaningful for the wind energy characterization of one given place, but it can also be seen as a useful analysis tool of the model wind simulations quality, because it depicts the sectorwise distribution of the winds with higher speed. Even if the occurrences wind rose shows significant deviations,

Table 7

Wind speed and direction statistical evaluation parameters e June 2008.

\begin{tabular}{|c|c|c|c|c|c|c|}
\hline \multirow[t]{2}{*}{ Physical options } & \multicolumn{2}{|l|}{ RMSE } & \multicolumn{2}{|l|}{ Bias } & \multicolumn{2}{|l|}{ STDE } \\
\hline & Speed $\left(\mathrm{m} \mathrm{s}^{-1}\right)$ & Direction $\left(^{\circ}\right)$ & Speed $\left(\mathrm{m} \mathrm{s}^{-1}\right)$ & Direction $\left(^{\circ}\right)$ & Speed $\left(\mathrm{m} \mathrm{s}^{-1}\right)$ & Direction $\left(^{\circ}\right)$ \\
\hline Simulation B.1 & 3.29 & 39.14 & -2.55 & -4.89 & 2.08 & 38.83 \\
\hline Simulation B.2 & 3.72 & 39.73 & -2.87 & -4.43 & 2.37 & 39.48 \\
\hline Simulation B.3 & 3.36 & 37.25 & -2.73 & -1.79 & 1.96 & 37.20 \\
\hline
\end{tabular}


these deviations can be due to low wind speeds that induce uncertainty in the wind direction simulation (and also measurement), and that are also not very significant in the local wind regime characterization.

The occurrence and energy wind roses, together with the wind speed histogram, are depicted in Fig. 6 for simulation B. 1 and in Fig. 7 for simulation B.3.

Fig. 6 clearly exposes the main errors of the model. The wind speed histogram shows the strong underestimation of the wind speed by the model: the more frequent wind speeds in the simulation are the ones between 2 and $5 \mathrm{~m} \mathrm{~s}^{-1}(14 \%)$, while the observed data shows that speeds between 5 and $7 \mathrm{~m} \mathrm{~s}^{-1}$ are the ones with higher frequency $(12 \%)$. In the direction, it is noticeable the difficulty of the model to accurately capture the dominant sectors. However, the energy wind rose shows a reasonably good agreement between simulated and observed data, meaning that the direction sectors that were not accurately simulated by the model are not very meaningful in terms of speed. For example, the sector east-southeast, which the model considered as the dominant one in terms of occurrences, has almost no expression in terms of energy, meaning that this sector has very low wind speeds and its direction can be subjected to higher errors during its measurement and/or simulation.

The same information for simulation B. 3 is now depicted in Fig. 7.

Fig. 7 reflects perfectly what was seen in Fig. 5 (b). This simulation captures very well the observed wind direction, namely the dominant sector (north-northwest). The fact that this simulation period (June 2008) is characterized by a clear dominant direction sector may contribute to the model good results in the wind direction simulation. The wind speed histogram of simulation B.3 confirms that, for this simulation period, the underestimation of the wind speed is higher. The more frequent wind speeds in the simulation are the ones between 3 and $5 \mathrm{~m} \mathrm{~s}^{-1}$ (almost 25\%), while the observed data shows that speeds between 7 and $9 \mathrm{~m} \mathrm{~s}^{-1}$ are the ones with more frequency (almost 20\%). The energy wind rose information reasserts the model good performance in the local wind regime characterization, showing that the model accurately simulated the wind direction and its respective wind speed rose.

The main conclusion that can be drawn is that the main model error is, in fact, the underestimation of the wind speed. It was seen that the wind direction is reasonably simulated by the model, especially in wind regimes where there is a very marked dominant sector. Also, it was seen that for January the model foresees significant frequencies of wind speeds between 1 and $2 \mathrm{~m} \mathrm{~s}^{-1}$. In these low wind speeds, the characterization of the direction (measured and simulated) is very subjective and can lead to higher deviations between simulations and observations. In June the modelled wind speeds are more constant (less occurrence of wind speeds below $4 \mathrm{~m} \mathrm{~s}^{-1}$ and above $12 \mathrm{~m} \mathrm{~s}^{-1}$ ) leading to more objective wind direction measurements and simulations that will produce lower deviations in terms of sectorwise frequencies.

Since the main limitation of the model is the underestimation of the wind speed, it becomes important to investigate possible a

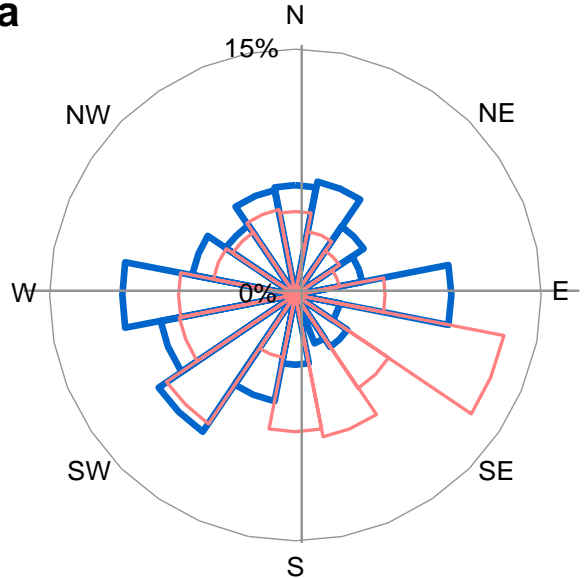

b 16

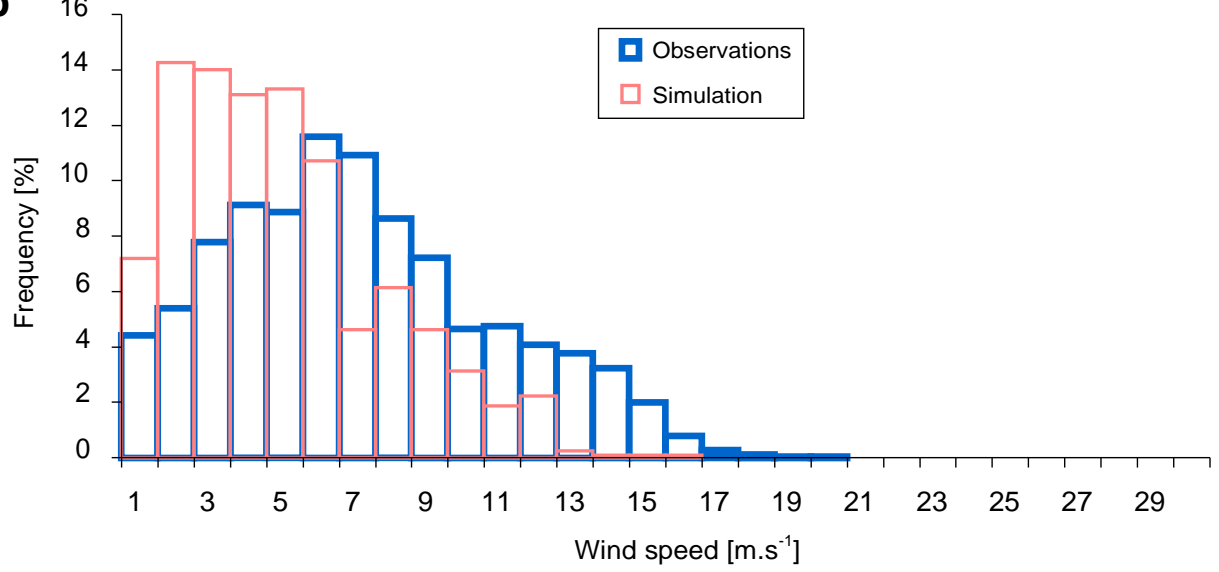

C

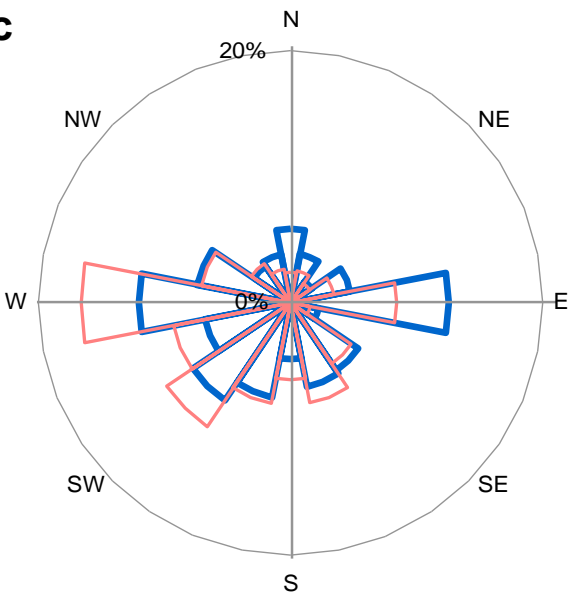

Fig. 6. Occurrence wind rose (a), wind speed histogram (b) and resulting energy wind rose (c) e Simulation B.1. 

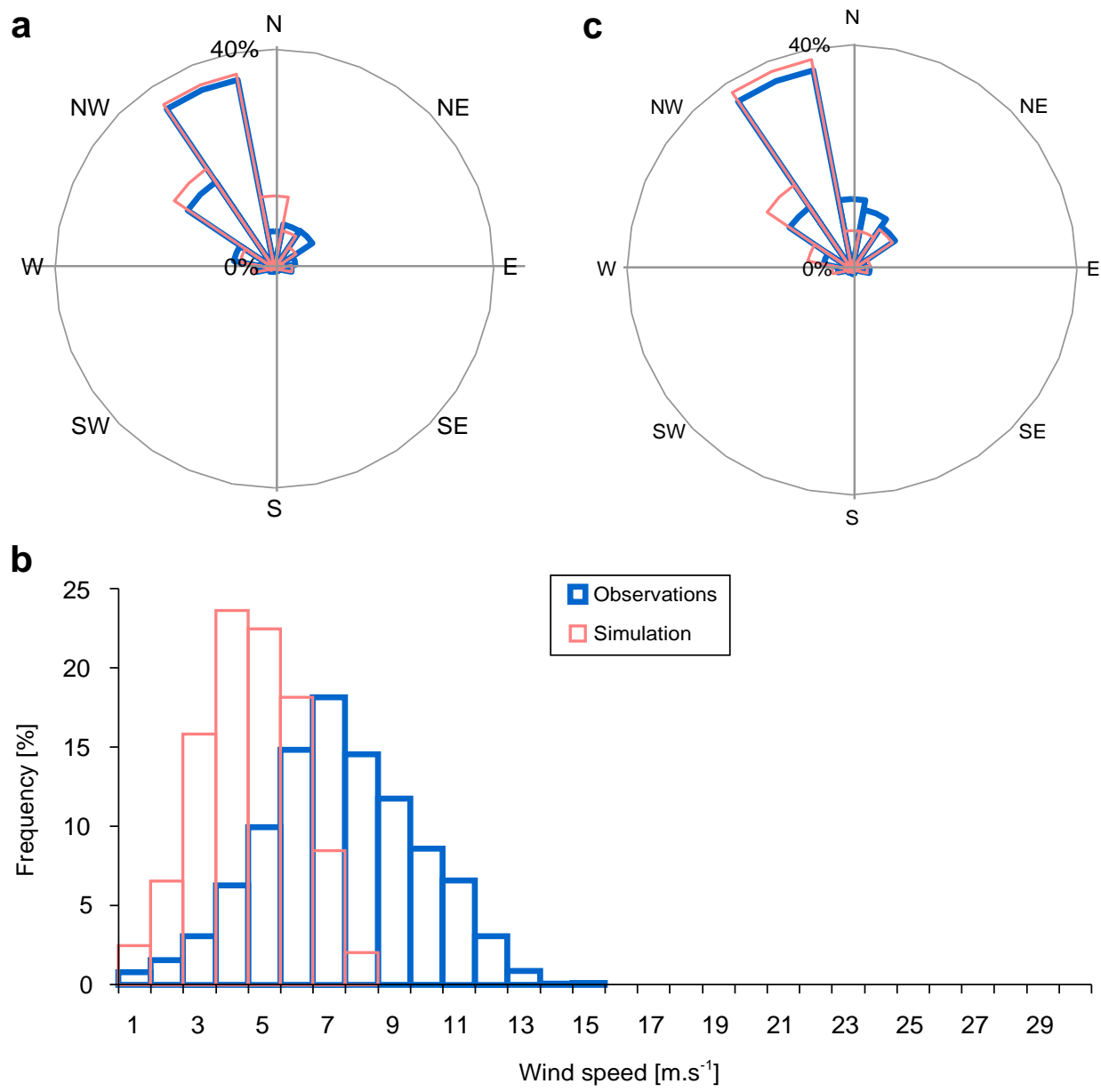

Fig. 7. Occurrence wind rose (a), wind speed histogram (b) and resulting energy wind rose (c) e Simulation B.3.

factors that can cause this model error. Given the fact that the wind measuring station considered until now is located in mountain area with significant elevation in complex terrain which, as stated in Section 1, are possible sources of errors in the model, the influence of the terrain complexity in the model results will be analyzed in the next section.

\subsection{Terrain complexity}

Table 8 summarizes the main characteristics of the three simulation points considered in this section, showing the differences between the real and the model represented elevation $(\Delta Z)$ for each point.

This information reasserts what was stated before, i.e. that this difference between the real elevation and model represented elevation of the simulation point (DZ) increases with the complexity of the surrounding terrain. The results are shown in Table 9.

Table 8

General characteristics of the simulation points.

\begin{tabular}{llllll}
\hline $\begin{array}{l}\text { Simulation } \\
\text { point }\end{array}$ & $\begin{array}{l}\text { Reference wind } \\
\text { measuring station }\end{array}$ & $\begin{array}{l}\text { Real } \\
\text { elevation }\end{array}$ & $\begin{array}{l}\text { Grid } \\
\text { elevation }\end{array}$ & DZ & $\begin{array}{l}\text { Terrain } \\
\text { complexity }\end{array}$ \\
\hline B.1 & WS1 & $556 \mathrm{~m}$ & $310 \mathrm{~m}$ & $246 \mathrm{~m}$ & Medium \\
C.1 & WS2 & $620 \mathrm{~m}$ & $336 \mathrm{~m}$ & $285 \mathrm{~m}$ & $\begin{array}{l}\text { Higher } \\
\text { L. } 2\end{array}$ \\
WS 3 & $489 \mathrm{~m}$ & $347 \mathrm{~m}$ & $143 \mathrm{~m}$ & Lower \\
\hline
\end{tabular}

Point C.2 (lower terrain complexity) is the one that presents better results, with lower RMSE, Bias and STDE. The simulation that has worse results (higher RMSE, Bias and STDE) is point C.1, the one whose point is located in the terrain with higher complexity. Point B.1 has intermediate results, which is consistent with its relative intermediate medium complexity terrain. To allow a better visualization of the results focusing on the wind speed model performance, Table 10 presents the monthly mean wind speed computed for each simulation and the respective observation data sets.

These results clearly reflect what was expected: as the terrain complexity increases, it also increases the model difficulties in accurately simulating the wind regime (especially the wind speed), being that the underestimation is significantly higher in locations with higher terrain complexity. The wind speed underestimation percentages are still significantly high, even for point C.2, but it has to be borne in mind that all simulation points used in this work are located in mountain areas with high terrain complexity.

Table 9

Wind speed and direction statistical evaluation parameters.

\begin{tabular}{|c|c|c|c|c|c|c|}
\hline \multirow{2}{*}{$\begin{array}{l}\text { Terrain } \\
\text { complexity }\end{array}$} & \multicolumn{2}{|l|}{ RMSE } & \multicolumn{2}{|l|}{ Bias } & \multicolumn{2}{|l|}{ STDE } \\
\hline & $\begin{array}{l}\text { Speed } \\
\left(\mathrm{m} \mathrm{s}^{-1}\right)\end{array}$ & $\begin{array}{l}\text { Direction } \\
\left({ }^{\circ}\right)\end{array}$ & $\begin{array}{l}\text { Speed } \\
\left(\mathrm{m} \mathrm{s}^{-1}\right)\end{array}$ & $\begin{array}{l}\text { Direction } \\
\left({ }^{\circ}\right)\end{array}$ & $\begin{array}{l}\text { Speed } \\
\left(\mathrm{m} \mathrm{s}^{-1}\right)\end{array}$ & $\begin{array}{l}\text { Direction } \\
\left({ }^{\circ}\right)\end{array}$ \\
\hline Point B.1 & 3.16 & 47.07 & -2.18 & -3.85 & 2.29 & 46.91 \\
\hline Point C.1 & 3.54 & 49.79 & -2.56 & -1.67 & 2.44 & 49.76 \\
\hline Point C.2 & 2.43 & 47.64 & -1.09 & -0.70 & 2.17 & 47.63 \\
\hline
\end{tabular}


Table 10

Comparison of the simulations mean wind speed

\begin{tabular}{llll}
\hline \multirow{2}{*}{ Simulation point } & \multicolumn{2}{l}{ Mean wind speed at $60 \mathrm{~m}$ a.g.l. $\left(\mathrm{m} \mathrm{s}^{-1}\right)$} & \multirow{2}{*}{ Deviation (\%) } \\
\cline { 1 - 2 } & Model & Observed & \\
\hline B.1 & 5.2 & 7.3 & -29 \\
C.1 & 5.0 & 7.6 & -34 \\
C. 2 & 5.0 & 6.1 & -18 \\
\hline
\end{tabular}

Table 11

General characteristics of the simulation points.

\begin{tabular}{llll}
\hline Simulation point & \multicolumn{2}{l}{ Elevation } & $\mathrm{D} z$ \\
\cline { 2 - 3 } & Real & Grid & \\
\hline B.1 & $556 \mathrm{~m}$ & $310 \mathrm{~m}$ & $246 \mathrm{~m}$ \\
D.1 & & $373 \mathrm{~m}$ & $183 \mathrm{~m}$ \\
\hline
\end{tabular}

This section shows that the terrain complexity is a key factor in the wind speed underestimation. Due to a weak terrain representation, the model considers the terrain smoother and with lower topography than it is in reality, and this will induce an underestimation of the wind speed in the simulations. On the one hand, places with lower elevation are typically characterized by lower mean wind speeds. As consequence, if the model considers the simulation point lower than it is in reality, the computed wind speed will be lower than in reality also. On the other hand, typically mountain areas are characterized by wind speed-up effects due to the fact that the wind becomes compressed on the windy side of the mountain, and once the air reaches the ridge it can expand again as its soars down into the low pressure area on the lee side of the mountain. If the model considers the terrain smoother and the simulation point lower than it is in reality, this speed-up effect will be lower and the simulated wind speeds will be underestimated. These two factors, that arise as consequences of the poor representation of the real terrain in the model simulation grid will, together, induce lower simulated wind speeds.

The simplest and logical way to try a better terrain representation in the model is to consider a new simulation domain with a higher resolution and evaluate the model performance. This new simulation domain with higher resolution should have, in theory, a better representation of the terrain and, thus, a lower DZ between real and model represented point elevation. Also, an increase of the vertical resolution of the simulation domain can produce effect in
Table 12

Wind speed and direction statistical evaluation parameters.

\begin{tabular}{|c|c|c|c|c|c|c|}
\hline \multirow{2}{*}{$\begin{array}{l}\text { Domain } \\
\text { resolution }\end{array}$} & \multicolumn{2}{|l|}{ RMSE } & \multicolumn{2}{|l|}{ Bias } & \multicolumn{2}{|l|}{ STDE } \\
\hline & $\begin{array}{l}\text { Speed } \\
\left(\mathrm{m} \mathrm{s}^{-1}\right)\end{array}$ & $\begin{array}{l}\text { Direction } \\
\left({ }^{\circ}\right)\end{array}$ & $\begin{array}{l}\text { Speed } \\
\left(\mathrm{m} \mathrm{s}^{-1}\right)\end{array}$ & $\begin{array}{l}\text { Direction } \\
\left({ }^{\circ}\right)\end{array}$ & $\begin{array}{l}\text { Speed } \\
\left(\mathrm{m} \mathrm{s}^{-1}\right)\end{array}$ & $\begin{array}{l}\text { Direction } \\
\left({ }^{\circ}\right)\end{array}$ \\
\hline Simulation B.1 & 3.16 & 47.07 & -2.18 & -3.85 & 2.29 & 46.91 \\
\hline Simulation D.1 & 3.03 & 42.47 & -1.99 & -1.26 & 2.28 & 42.45 \\
\hline
\end{tabular}

the results, due to a better discretization of the lower atmosphere. This test is performed in the following section.

\subsection{Simulation domain resolution}

The domain resolution was increased from 3.6 to $1.2 \mathrm{~km}$, with additional 23 vertical layers. As expected, the higher horizontal resolution in the simulation domain reduces the $\mathrm{DZ}$ between real and model represented point elevation, as it can be seen in Table 11. The results are presented in Fig. 8 and Table 12 .

Analyzing Fig. 8 and Table 12, it is clear that simulation D.1 is the one that presents better results, with lower RMSE, Bias and STDE for wind speed and direction. This test shows that a more accurate representation of the terrain and/or the boundary layer can produce better results, in part due to lower differences between real and model grid terrain characteristics. However, model performance using finer horizontal and vertical spacing may be better, worse, or similar, due to uncertainties in the performance of the various physical parameterizations and their responses to grid resolution (Queen and Zhang, 2008; Jang et al., 1995; Wu et al., 2008; Zhang et al., 2006a, b). While several studies reported that increasing grid resolution may lead to better reproduction of finescale meteorological processes (e.g., Jimenez et al., 2006; Liu and Westphal, 2001; Mass et al., 2002) this may not necessarily correlate to better model accuracy (Gego et al., 2005).

Following the conclusions of these authors, it is also seen with this test that the differences between the simulations are not very significant when the horizontal and vertical resolution of the simulation domain is improved. Also, the computational costs of simulation D.1 are much higher than the ones needed for simulation B.1. Consequently, it is important to perform a careful "results improvement vs. computational cost" analysis when choosing the simulation domain resolution.
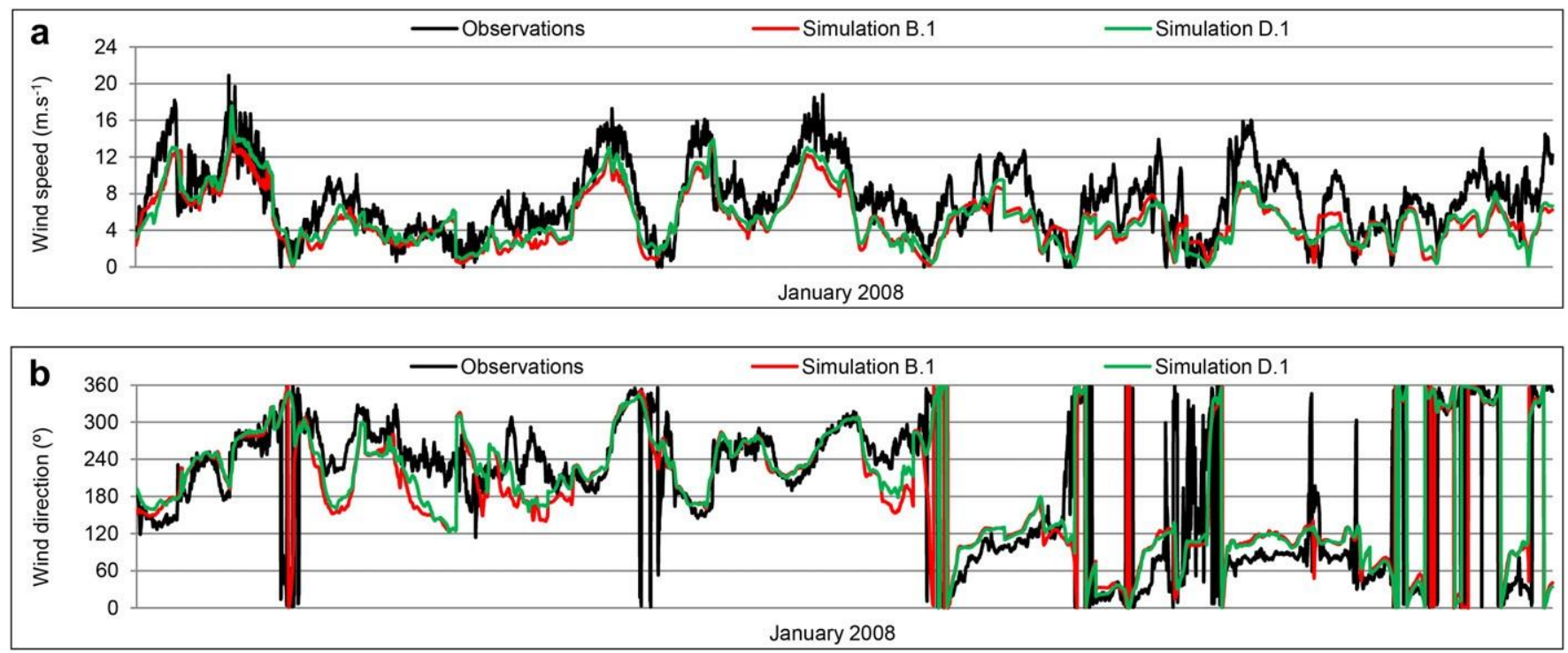

Fig. 8. Wind speed (a) and direction (b) time series. 


\section{Conclusions}

Several tests with the WRF meteorological model were performed, aiming to evaluate the use of different numerical and physical options in the simulation of the near-surface wind speed and direction, as well as the influence of the simulation domain resolution and terrain complexity in the model performance. An area characterized by intensive wind energy exploration, due to its significant available wind resource, with relatively high terrain complexity was chosen to conduct the simulations, where available measured wind data collected at $60 \mathrm{~m}$ a.g.l. was used to evaluate the model performance.

Three different numerical configurations of the model were evaluated, showing that there are advantages in using the grid nudging option in simulations that should not exceed the 2 days of integration time, in order to avoid possible divergences of the model. Using this methodology the model is continuously restarted, removing the errors accumulated during each integration period and allowing the model not to diverge from the analyses and/or observations over the integration time.

Three different sets of parameterizations schemes regarding the boundary layer (SL, PBL and LSM) were tested, for different seasonal conditions (a summer and a winter month). The SLePBLeLSM parameterization set composed by the schemes MM5eYSUeNoah was the one with better performance for January, and the set that considered the schemes PXeACM2ePX presented better results for June, explained by the fact that in cold seasons these schemes have a tendency to consider an excessive cloud coverage at the top of the PBL, which has a significant impact on the maximum daily temperature in some areas. Overall, the model presented a better performance for January, and this can be explained by the fact that, in warm seasons, the small scale processes have a larger influence compared to winter because the large scale forcing is weaker. The parameterization set MM5eYSUeNoah was the one with better overall performance (better results in the winter month and a reasonable performance in the summer one), due to the limitations of the schemes PXeACM2ePX to simulate cold seasons. All these findings highlight the vital importance of realistic parameterizations of sub-grid scale processes. Therefore, for high resolution near-surface wind simulations the PBL, SL and LSM schemes should be chosen carefully. A more detailed analysis of the model results showed that, in fact, the wind speed underestimation is one of the main limitations of the model. The wind direction is reasonably simulated by the model, especially in wind regimes where there is a very marked dominant sector. Although significant deviations in the wind direction simulation were seen, especially in January, the analysis of the energy wind rose showed that the direction sectors that were wrongly simulated by the model are characterized by low wind speeds that are not very significant in the local wind regime. Also, for low wind speeds the direction measurements or simulation is somewhat subjective. The model is able to accurately characterize the local flow in terms of energy content and distribution, which can be an asset and factor of interest to wind energy agents when considering the use of mesoscale models in wind energy preliminary assessment.

The model also revealed significant sensitivity to the local terrain complexity when simulating the wind speed, since it was shown that the wind speed underestimation increases greatly in places with higher terrain complexity. Due to the weak representation of the real topography and terrain features in the model simulation grid, the higher the real local terrain complexity, the higher will be the differences between real and model represented terrain characteristics, which will induce lower wind speed simulations: on the one hand, if the model considers the simulation point lower than it is in reality, the wind speed-up effects will be lower; on the other hand, places with lower elevation are typically characterized by lower mean wind speeds.

An attempt to minimize these factors that cause wind speed underestimation was made, increasing the simulation domain resolution to obtain a better terrain representation, meaning lower differences between real and model represented terrain. The consideration of a simulation domain with higher resolution (horizontal and vertical) offers a more accurate representation of the local terrain and of the lower atmosphere, especially in the boundary layer. The results showed a slight improvement on the simulations accuracy, however, this improvement does not seem to compensate for the high associated computational costs. This can be seen as a signal that, below a determined domain resolution, the model performance is not significantly improved with the increase of the domain resolution.

These results suggest that error minimization in the wind simulation can be achieved by testing and choosing a suitable model configuration (both numerical and physical) for the region of interest. When determining the simulation grid characteristics, there should be a compromise between the chosen resolution and available computational resources, since a high domain resolution may not compensate for the associated computational costs. Also, the simulations performed by this model should be used with caution in areas with high terrain complexity, and the use of more detailed terrain data in the model is advised, if possible.

\section{References}

Arya, P.S., 1988. Introduction to Micrometeorology. Academic Press, Orlando.

Awan, N.K., Gobiet, A., Truhetz, H., 2011. Parameterization induced error-characteristics of MM5 and WRF operated in climate mode over the Alpine Region: an ensemble based analysis. J. Clim. 24, 3107e3123.

Barnsley, M.J., 2007. Environmental Modeling: A Practical Introduction. CRC Press, Boca Raton, FL.

Blackadar, 1979. High-resolution models of the planetary boundary layer. In: Pfafflin, J., Ziegler, E. (Eds.), Advances in Environmental Science and Engineering, vol. 1. Gordon and Breach, pp. 50e85.

Borge, R., Alexandrov, V., del Vas, J.J., Lumbreras, J., Rodriguez, E., 2008. A comprehensive sensitivity analysis of the WRF model for air quality applications over the Iberian Peninsula. Atmos. Environ. 42, 8560 e8574.

Byrkjedal, O., Berge, E. 2008. The Use of WRF for Wind Resource Mapping in Norway. In: The 9th WRF Users' Workshop, NCAR Green Campus. http://www. $\mathrm{mmm}$.ucar.edu/wrf/users/workshops/WS2008/WorkshopProgram.pdf.

Chagas, G.O., Guedes, R.A., Manso, M.D.O., 2009. Estimating wind resource using mesoscalemodeling.In:The European Wind Energy Conference EWEC 2009.http:// www.ewec2009proceedings.info/allfiles2/638_EWEC2009presentation.pdf.

Challa, V.S., Indracanti, J., Rabarison, M.K., et al., 2007. Numerical experiments on the sensitivity of WRF-CMAQ simulations of air quality in the Mississippi Gulf coastal region to PBL and Land surface models. In: The 6th Annual CMAS Conference, Chapel Hill, NC, October 1e3, 2007. http://www.cmascenter.org/ conference/2007/agenda.cfm.

Challa, V.S., Indracanti, J., Rabarison, M.K., Patrick, C., Baham, J.M., Young, J., Hughes, R., Hardy, M.G., Swanier, S.J., Yerramilli, A., 2009. A simulation study of mesoscale coastal circulations in Mississippi Gulf coast. Atmos. Res. 91, 9e25.

Chigullapalli, S., Mölders, N., 2008. Sensitivity studies using the weather research and forecasting (WRF) model. ARSC Report, 15.

Ferreira, P., Castanheira, J.M., Rocha, A., Ferreira, J., 2008. Estudo de sensibilidade das previsões de superfície em Portugal, pelo WRF, face à variação das parametrizações físicas. XXX Jornadas Científicas de la Associación Meteorológica Española, Zaragoza. http://www.ame-web.org/index.php?option 1/4 com content\&view 1/4article\&id1/4 69:xxx-jornadas-cientificas-de-la-amezaragoza\&catid $1 / 4$ 35:jornadas-cientificas\&Itemid 1/497.

Gallus Jr., W.A., Bresch, J.F., 2006. Comparison of impacts of WRF dynamic core, physics package, and initial conditions on warm season rainfall forecasts. Mon. Weather. Rev. 134 (9), 2632e 2641.

Gego, E., Hogrefe, C., Kallos, G., Voudouri, A., Irwin, J.S., Rao, S.T., 2005. Examination of model predictions at different horizontal grid resolutions. Environ. Fluid. Mech. 5, 63e85.

Gilliam, R.C., Pleim, J., Xiu, A., 2007. Implementation of the Pleim-Xiu land surface model and asymmetric convective model in the WRF Model. In: The 8th Annual WRF Users workshop. http://www.mmm.ucar.edu/wrf/users/workshops/ WS2007/abstracts/5-7_Gilliam.pdf.

Gilliam, R.C., Pleim, J., 2010. Performance assessment of new land surface and planetary boundary layer physics in the WRF-ARW. J. Clim. Appl. Meteorol. 49 (4), $760 \mathrm{e} 774$. 
Han, Z., Ueda, H., An, J., 2008. Evaluation and intercomparison of meteorological predictions by five MM5-PBL parameterizations in combination with three landsurface models. Atmos. Environ. 42, 233e249.

Hirabayashi, S., Kroll, C.N., Nowak, D.J., 2011. Component-based development and sensitivity analyses of an air pollutant dry deposition model. Environ. Modell. Softw. 26 (6), 804e816.

Hong, S.-Y., Pan, H.-L., 1996. Nonlocal boundary layer vertical diffusion in a mediumrange forecast model. Mon. Weather Rev. 124, $2322 \mathrm{e} 2339$.

Hutchinson, T.A., Sousounis, P., Marshall, S., 2005. WRF enhancements for opera tional simulations. In: The WRF/MM5 User's Workshop. http://www.mmm. ucar.edu/wrf/users/workshops/WS2005/abstracts/Session2/2-Hutchinson.pdf.

Jang, J.C., Jeffries, H.E., Byun, D., Pleim, J.E., 1995. Sensitivity of ozone to model grid Resolution: part I Application of high-resolution regional acid deposition model. Atmos. Environ. 29, 3085e3100.

Janjic, Z.I., 1994. The step-mountain Eta coordinate model: further developments of the convection, viscous sublayer, and turbulence closure schemes. Mon. Weather. Rev. 122, 927e945.

Jankov, I., Gallus, J.W.A., Segal, M., Shaw, B., Koch, S.E., 2005. The impact of different WRF model physical parameterizations and their interactions on warm season MCS rainfall. Weather Forecast 20 (6), 1048e1060.

Jankov, I., Schultz, P.J., Anderson, C.J., Koch, S.E., 2007. The impact of different physical parameterizations and their interactions on cold season QPF in the American River basin. J. Hydromet. 8, 1141e1151.

Jimenez, P., Jorba, O., Parra, R., Baldasano, J.M., 2006. Evaluation of MM5EMICAT2000-CMAQ performance and sensitivity in complex terrain: highresolution application to the northeastern Iberian Peninsula. Atmos. Environ. 40 (26), 5056e5072.

Kain, J.S., Fritsch, J.M., 1990. A one-dimensional entraining/detraining plume model and its application in convective parameterization. J. Atmos. Sci. 47, $2784 \mathrm{e} 2802$.

Kain, J.S., Fritsch, J.M., 1993. Convective parameterization for mesoscale models: the KaineFritcsh scheme. In: Emanuel, K.A., Raymond, D.J. (Eds.), The Representation of Cumulus Convection in Numerical Models. Amer. Meteor. Soc, p. 246.

Kapos, V., Rhind, J., Edwards, M., Price, M.F., Ravilious, C., 2000. Developing a map of the world's mountain forests. In: Price, M.F., Butt, N. (Eds.), Forests in Sustainable Mountain Development: A State of Knowledge Report for 2000. CAB International, Wallingford, pp. 4e9.

Krieger, J.R., Zhang, J., Atkinson, D.E., Shulski, M.D., Zhang, X., 2009. Sensitivity of WRF model forecasts to different physical parameterizations in the Beaufort Sea region. In: The Eighth Conference on Coastal Atmospheric and Oceanic Prediction and Processes. http://ams.confex.com/ams/pdfpapers/150439.pdf.

Kumar, S., Peters-Lidard, C.D., Eastman, J.L., Tao, W.-K., 2008. An integrated high resolution hydrometeorological modeling testbed using LIS and WRF. Environ. Modell. Softw. 23 (2), 169e181.

Liu, M., Westphal, D.L., 2001. A study of the sensitivity of simulated mineral dust production to model resolution. J. Geophys. Res. 106 (18). doi:10.1029/ 2000JD900711, pp. 099e18, 112

Mass, C.F., Ovens, D., Westrick, K., Cole, B.A., 2002. Does increasing horizontal resolution produce more skillful forecasts? Bull. Amer. Meteor. Soc, 407e430.

Mellor, G.L., Yamada, T., 1974. Development of a turbulence closure model for geophysical fluid problems. Rev. Geophys. Space. Phys. 20, 851e875.
Noh, Y., Cheon, W.-G., Hong, S.-Y., 2003. Improvement of the K-profile model for the planetary boundary layer based on large eddy simulation data. Boundary-Layer Meteorol. 107, 401e427.

Nossent, J., Elsen, P., Bauwens, W., 2011. Sobol' sensitivity analysis of a complex environmental model. Environ. Modell. Softw. 26 (12), 1515 e1525.

Orlanski, I., 1975. Rational subdivision of scales for atmospheric processes. Bull. Amer. Meteor. Soc. 56 (5), 527e530.

Pagowski, M., 2004. Some comments on PBL parameterizations in WRF. In: Joint 5th WRF/14th MM5 users' workshop, Boulder, CO, NCAR, pp. 43e46 (Preprints). http://www.mmm.ucar.edu/mm5/workshop/workshop-papers_ws04.html.

Papanastasiou, D.K., Melas, D., Lissaridis, I., 2010. Study of wind field under sea breeze conditions; an application of WRF model. Atmos. Res. 98 (1), $102 \mathrm{e} 117$.

Pielke Sr., R.A., 2002. Mesoscale Meteorological Modeling, second ed. Academic Press, San Diego, CA.

Queen, A., Zhang, Y., 2008. Examining the sensitivity of MM5-CMAQ predictions to explicit microphysics schemes and horizontal grid resolutions, Part IIId the impact of horizontal grid resolution. Atmos. Environ. 42, 3869e3881.

Shafran, P.C., Seaman, N.L., Gayno, G.A., 2000. Evaluation of numerical predictions of boundary layer structure during the Lake Michigan Ozone Study. J. Appl. Meteorol. 39 (3), 412e426.

Shin, H.H., Hong, S.-Y., 2011. Intercomparison of planetary boundary layer parameterizations in the WRF model for a single day from Cases 99. Boundary-Layer Meteorol. 139, 261e281.

Soares, A., Pinto, P., Pilão, R., 2010. Mesoscale modelling for wind resource evaluation purposes: a test case in complex terrain. In: International Conference on Renewable Energies and Power Quality 2010. http://www.icrepq.com/ icrepq'10/433-Soares.pdf.

Skamarock, W.C., Klemp, J.B., Dudhia, J., Gill, D.O., Barker, D.M., Huang, X.Y., Wang, W., Powers, J.G., 2008. A Description of the Advanced Research WRF Version 3, NCAR TECHNICAL NOTE, NCAR/TN-475 pSTR, pp. 113.

Stauffer, D.R Seaman, N.L., 1990. Use of four-dimensional data assimilation in a limited-area mesoscale model Part I: experiments with synoptic-scale data Mon. Wea. Rev. 118, 1250e1277.

Stauffer, D.R., Seaman, N.L., Binkowski, F.S., 1991. Use of four-dimensional data assimilation in a limited-area mesoscale model Part II: effects of data assimilation within the planetary boundary layer. Mon. Wea. Rev. 119, 734e754 Wakes, S.J., Maegli, T., Dickinson, K.J., Hilton, M.J., 2010. Numerical modelling of wind flow over a complex topography. Environ. Modell. Softw. 25 (2), 237e247. Wu, S.Y., Krishnan, S., Zhang, Y., Aneja, V., 2008. Modelling atmospheric transport an fate of ammonia in north Carolina part I: evaluation of meteorological and chemical predictions. Atmos. Environ. 42, 3419e3436.

Zhang, D.L., Anthes, R.A., 1982. A high-resolution model of the planetary boundary layer-sensitivity tests and comparisons with SESAME-79 data. J. Appl. Meteorol 21, $1594 \mathrm{e} 1609$

Zhang, Y., Liu, P., Pun, B., Seigneur, C., 2006a. A comprehensive performance eval uation of MM5-CMAQ for the Summer 1999 southern oxidants study episode part I: evaluation protocols, databases and meteorological predictions. Atmos. Environ. 40, 4825e4838.

Zhang, Y., Liu, P., Queen, A., Misenis, C., Pun, B., Seigneur, C., Wu, S.Y., 2006b. A comprehensive performance evaluation of MM5-CMAQ for the summer 1999 southern oxidants study episode part II: gas and aerosol predictions. Atmos. Environ. 40, 4839e4855. 